Provided for non-commercial research and education use. Not for reproduction, distribution or commercial use.

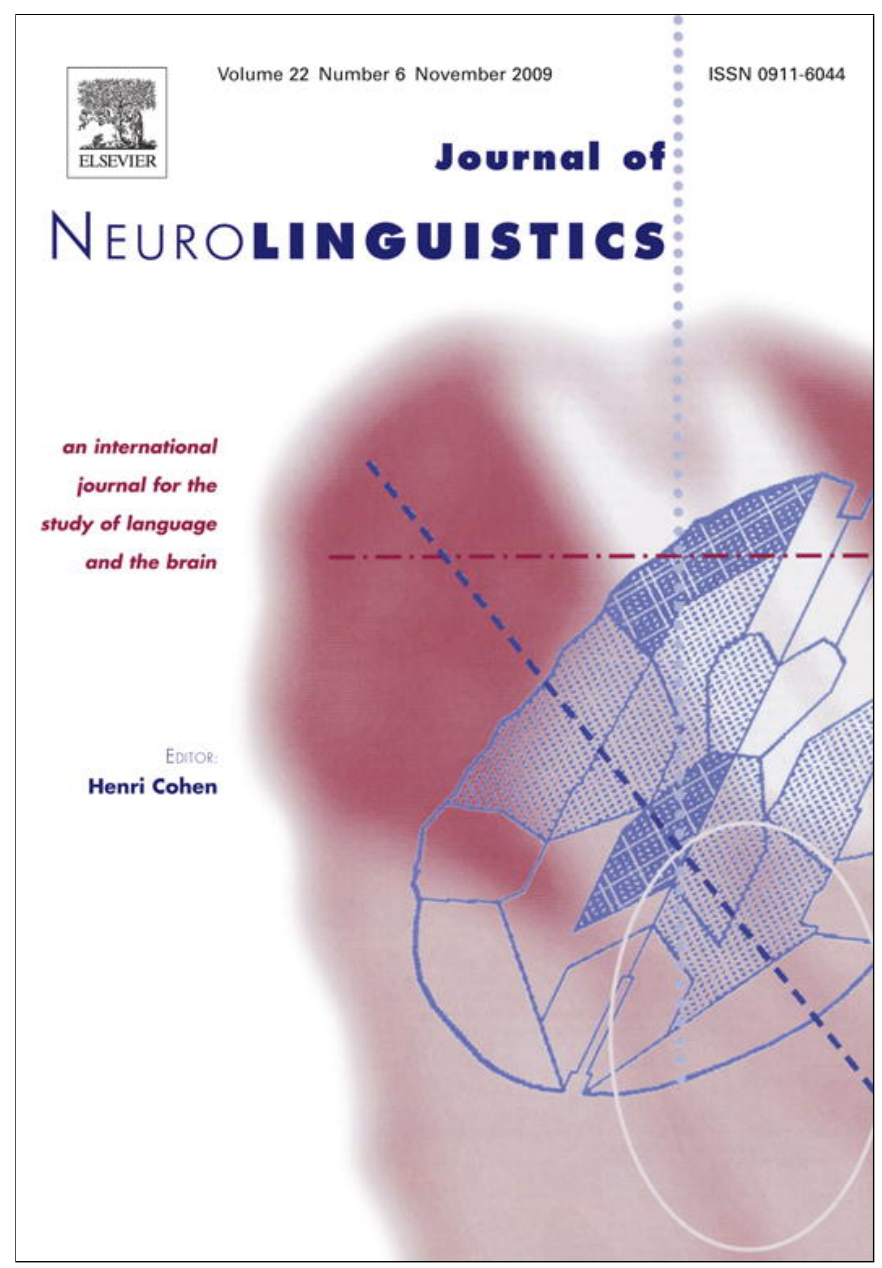

This article appeared in a journal published by Elsevier. The attached copy is furnished to the author for internal non-commercial research and education use, including for instruction at the authors institution and sharing with colleagues.

Other uses, including reproduction and distribution, or selling or licensing copies, or posting to personal, institutional or third party websites are prohibited.

In most cases authors are permitted to post their version of the article (e.g. in Word or Tex form) to their personal website or institutional repository. Authors requiring further information regarding Elsevier's archiving and manuscript policies are encouraged to visit:

http://www.elsevier.com/copyright 


\title{
"L" is for tiger: Effects of phonological (mis)cueing on picture naming in semantic aphasia
}

\author{
Maya Soni, Matthew A. Lambon Ralph, Krist Noonan, Sheeba Ehsan, \\ Catherine Hodgson, Anna M. Woollams*
}

Neuroscience and Aphasia Research Unit, School of Psychological Sciences, Zochonis Building, University of Manchester, Brunswick Street, Manchester, M13 9PL, England, UK

\section{A R T I C L E I N F}

\section{Article history:}

Received 30 April 2009

Received in revised form 10 June 2009

Accepted 16 June 2009

\section{Keywords:}

Cueing

Picture naming

CVA

Stroke

Aphasia

Semantic memory

Executive control

Speech production

\begin{abstract}
A B S T R A C T
Semantic aphasia (SA) refers to a subset of aphasic patients who exhibit multimodal semantic deficits (Jefferies, E., \& Lambon Ralph, M. (2006). Semantic impairment in stroke aphasia vs semantic dementia: a case-series comparison. Brain, 129(8), 2132-2147). Consistent with their underlying semantic control deficit, SA picture naming accuracy can be improved considerably with a correct phonological cue. The performance of normal individuals in the tempo picture naming paradigm reveals an increased impact of both correct and incorrect phonological cueing, and it has been suggested that this technique reduces resources available for semantic control in neurologically-intact participants (Hodgson, C., \& Lambon Ralph, M. (2008). Mimicking aphasic semantic naming errors in normal speech production: Evidence from a novel experimental paradigm. Brain and Language, 104(1), 89-101.). We tested this hypothesis by considering the impact of both correct and incorrect phonological cues on picture naming in a case series of SA patients, using exactly the same items as those presented to normal participants for tempo naming. The results confirmed the positive effect of correct cues and revealed for the first time the negative effects of category co-ordinate miscues amongst these patients in both overall accuracy and semantic error rates. The implications of our results for current speech production models are considered.
\end{abstract}

(c) 2009 Elsevier Ltd. All rights reserved.

\footnotetext{
* Corresponding author. Tel.: +44 161306 0453; fax: +44 1612752873.

E-mail address: anna.woollams@manchester.ac.uk (A.M. Woollams).
} 


\section{Introduction}

The ability to harness semantic knowledge effectively in service of a task is dependent on two interactive component abilities: the representation of meaning and its utilisation in an appropriate manner. To date, many studies of semantic dementia (SD), a progressive disorder of semantic memory caused by anterior temporal lobe atrophy, have clearly demonstrated that the consequence of degradation of semantic representations is a multimodal semantic deficit (Bozeat, Lambon Ralph, Patterson, \& Hodges, 2000; Bozeat et al., 2003). Multimodal semantic deficits have also been observed amongst some stroke aphasic patients (Chertkow, Bub, Deaudon, \& Whitehead, 1997; Jefferies \& Lambon Ralph, 2006) who most commonly have prefrontal and temporo-parietal infarcts. To distinguish this subset of aphasic patients from those who have modality-specific comprehension impairment alone, the label semantic aphasia (SA) was proposed as a short-hand term. Superficially, the pattern of performance seen in SA patients (especially those with transcortical sensory aphasia) might appear to resemble that seen in SD patients; however a direct comparison shows some key qualitative differences. The semantic impairment associated with SD reflects a progressive degradation of core, amodal semantic representations (Bozeat et al., 2000; Bozeat et al., 2003; Rogers et al., 2004). In contrast, impaired semantic performance in SA arises as a result of difficulties with online shaping of activation generated by intact semantic representations (Jefferies \& Lambon Ralph, 2006).

These different underlying impairments to semantically-driven behaviour produce contrasting patterns of performance on semantic tests. Specifically, SA patients differ from SD patients in terms of the consistency of their performance across semantic tests with differing task requirements (low in SA but high in SD) and an absence of effects of familiarity/frequency for SA but strong effects in SD (Jefferies \& Lambon Ralph, 2006). There is also a correlation in SA but not SD between tests of executive function and semantic measures (Jefferies \& Lambon Ralph, 2006), supporting the notion that the deficits observed in SA arise from an inability to effectively utilise semantic knowledge as a result of compromised control processes.

The different nature of the semantic cognition impairments in SD and SA are also apparent in picture naming (Jefferies, Baker, Doran, \& Lambon Ralph, 2007; Jefferies \& Lambon Ralph, 2006; Jefferies, Patterson, \& Lambon Ralph, 2008). All models of speech production would concur that the process of picture naming involves identification of the depicted object within the semantic system and retrieval of the phonological form corresponding to its name. Hence any disruption to the semantic system will undermine picture naming in terms of compromising input to the phonological system. The semantic control impairment observed amongst SA patients is reflected in the presence of associative naming errors, such as "nuts" for SQUIRREL, which indicate that details of the correct target are still being reached, but an inappropriate element is selected (Jefferies \& Lambon Ralph, 2006; Jefferies et al., 2008). Such naming responses are almost never observed in SD patients, whose commission errors are most often category co-ordinate responses (Woollams, Cooper-Pye, Hodges, \& Patterson, 2008).

Unlike SD, SA is not a uniform condition with a single organic origin; rather, it is a common set of deficits occurring across a somewhat heterogeneous population. Patients were included in this SA case series if they failed both word and picture versions of semantic association tests such as the Camel and Cactus Test or CCT (Bozeat et al., 2000) and/or the Pyramids and Palm Trees Test or PPT (Howard \& Patterson, 1992). Their lesion locations are provided in Table 1, with scans for five of the seven patients provided in Appendix A in the Supplementary Materials. As can be inferred from the variability in lesion location in our case series, we are do not assign semantic control ability to a single site. Problems with semantic control co-occur with frontal and/or temporo-parietal lesions (Jefferies \& Lambon Ralph, 2006; Noonan, Jefferies, Corbett, Hopper, \& Lambon Ralph, in press), pointing to a distributed system. Transcortical sensory aphasic patients with either frontal or parietal lesions show a similar pattern of deficits regardless of lesion location (Berthier, 2001), and similar deficits in non-language attentional function occur with both frontal or parietal lesions (Peers et al., 2005). In imaging studies with normal participants, the manipulation of semantic information also appears to rest on a network of parietal and frontal regions (Cristescu, Devlin, \& Nobre, 2006; Devlin, Matthews, \& Rushworth, 2003), as do non-language executive control functions such as inhibition of task-irrelevant material (Collette, Hogge, Salmon, \& Van der Linden, 2006; Collette, Olivier, et al., 2005; Collette, Van der Linden et al., 2005). 
Table 1

SA patients' biographical details, lesion characteristics and patterns of co-occurrence.

\begin{tabular}{|c|c|c|c|c|c|c|c|c|c|c|c|c|c|c|c|c|c|c|c|c|}
\hline \multirow[t]{2}{*}{ Patient } & \multirow[t]{2}{*}{ Age } & \multirow[t]{2}{*}{ Sex } & \multirow{2}{*}{$\begin{array}{l}\text { Educ } \\
\text { leaving } \\
\text { age }\end{array}$} & \multirow{2}{*}{$\begin{array}{l}\text { Years } \\
\text { since } \\
\text { CVA }\end{array}$} & \multirow{2}{*}{$\begin{array}{l}\text { Lesion size } \\
\text { (\% of template }_{\text {damaged })^{\mathrm{a}}}\end{array}$} & \multirow{2}{*}{$\begin{array}{l}\text { Frontal } \\
\text { damage }\end{array}$} & \multirow{2}{*}{$\begin{array}{l}\text { Temporo } \\
\text { parietal } \\
\text { damage }\end{array}$} & \multicolumn{2}{|c|}{ DLPFC } & \multirow{2}{*}{$\frac{\text { orbIFC }}{\text { BA } 47}$} & \multirow{2}{*}{$\begin{array}{l}\text { trIFG } \\
\text { BA 45 }\end{array}$} & \multirow{2}{*}{$\begin{array}{l}\text { opIFG } \\
\text { BA } 44\end{array}$} & \multirow{2}{*}{$\begin{array}{l}\text { STG } \\
\text { BA 22 }\end{array}$} & \multirow{2}{*}{$\frac{\text { MTG }}{\text { BA } 21}$} & \multirow{2}{*}{$\frac{\text { ITG }}{\text { BA 20 }}$} & \multirow{2}{*}{$\frac{F G}{B A 36}$} & \multirow{2}{*}{$\begin{array}{l}\text { POT } \\
\text { BA } 37\end{array}$} & \multirow{2}{*}{$\begin{array}{l}\text { AG } \\
\text { BA } 39\end{array}$} & \multirow{2}{*}{$\begin{array}{l}\text { SMG } \\
\text { BA } 40\end{array}$} & \multirow{2}{*}{$\begin{array}{l}\text { TP } \\
\text { BA } 38\end{array}$} \\
\hline & & & & & & & & $\overline{\text { BA } 9}$ & BA 46 & & & & & & & & & & & \\
\hline NY & 67 & M & 15 & 8 & 14 & $\nu$ & $\nu$ & 1 & 1 & 2 & 2 & 2 & 1 & - & - & - & - & 2 & 2 & - \\
\hline $\mathrm{HN}$ & 77 & M & 15 & 2 & 6 & $x$ & $\nu$ & - & - & - & - & - & - & 2 & 1 & - & 2 & w & - & - \\
\hline $\mathrm{JD}^{\mathrm{b}}$ & 68 & M & 16 & 11 & & $x$ & w & & & & & & & & & & & & & \\
\hline $\mathrm{PG}^{\mathrm{C}}$ & 63 & M & 18 & 8 & & $\nu$ & w & & & & & & & & & & & & & \\
\hline SC & 80 & M & 16 & 8 & 8 & $\times$ & $r$ & - & - & - & - & - & - & - & 2 & - & 2 & 2 & w & - \\
\hline $\mathrm{BB}^{\mathrm{d}}$ & 59 & $\mathrm{~F}$ & 16 & 6 & 3 & $\nu$ & $\nu$ & - & - & 2 & 2 & 2 & 2 & - & - & - & - & - & - & - \\
\hline ME & 40 & $\mathrm{~F}$ & 16 & 9 & 5 & $x$ & $r$ & - & - & - & - & - & - & 2 & 2 & 2 & 2 & w & w & - \\
\hline \multicolumn{8}{|c|}{$\%$ patients with grey matter damage } & 20 & 20 & 40 & 40 & 40 & 40 & 40 & 60 & 20 & 60 & 40 & 20 & 0 \\
\hline \multicolumn{8}{|c|}{$\%$ patients with grey or white matter damage } & 20 & 20 & 40 & 40 & 40 & 40 & 40 & 60 & 20 & 60 & 80 & 60 & 0 \\
\hline
\end{tabular}

Patients are arranged in order of naming scores in the 64 item battery (Bozeat et al., 2000).

Anatomical abbreviations: DLPFC = dorsolateral prefrontal cortex; orbIFG = pars orbitalis in inferior frontal gyrus; trIFG, = pars triangularis in inferior frontal gyrus; opIFG = pars opercularis in inferior frontal gyrus; $\mathrm{TP}=$ temporal pole; $\mathrm{STG}=$ superior temporal gyrus; $\mathrm{MTG}=$ middle temporal gyrus; $\mathrm{ITG}=$ inferior temporal gyrus; $\mathrm{FG}=$ fusiform gyrus; $\mathrm{POT}=$ posterior occipitotemporal area; $\mathrm{SMG}=$ supramarginal gyrus; $\mathrm{AG}=$ angular gyrus.

Quantification of lesion: 2 = complete destruction/serious damage to cortical grey matter; 1 = partial destruction/mild damage to cortical grey matter; $\mathrm{w}=$ damage confined to white matter immediately underlying cortex.

${ }^{a}$ Lesion size was estimated by overlaying a standardised grid of squares onto each patient's template and working out the percentage of squares damaged relative to the complete undamaged template.

b No scan available. Description of lesion: L putamen and capsule.

${ }^{c}$ No scan available. Description of lesion: $L$ frontal and capsular.

${ }^{d}$ BB showed additional signs of ventricular enlargement in the left hemisphere. 
Consistent with the notion of an underlying control impairment, the picture naming performance of SA patients shows a much larger improvement in performance than SD patients when provided with a correct phonological cue, such a /t/ for a picture of a tiger (Jefferies et al., 2007; Jefferies \& Lambon Ralph, 2006; Jefferies et al., 2008). A corollary of the improved SA performance with correct phonological cues is that an appreciable decrement should be observed when the cue corresponds to a semantically related target (e.g. providing / $1 /$ with TIGER should boost activation of the competitor lion). A number of stroke aphasic patients with intact comprehension have been found to show significant effects of correct cueing (EST, Kay \& Ellis, 1987; GM, Lambon Ralph, Sage, \& Roberts, 2000; LM, Howard \& Gatehouse, 2006) and miscueing (LS, Lambon Ralph, Sage, \& Roberts, 2000). In one case of comprehension impairment that seemed limited to verbal stimuli, pronounced effects of both cueing and miscueing were also apparent (JCU, Howard \& Orchard Lisle, 1984). Most comparable to the SA patients considered here are two cases reported by Howard and Gatehouse (2006), both of whom showed impaired verbal and non-verbal comprehension. One case (JGr) showed effects of both cueing and miscueing using initial phonemes, whereas the other (KS) showed only an effect of miscueing. Given variations in the cueing effects observed in these case studies, the first aim of the present study was therefore to apply this method to a case series of SA patients in order to confirm the positive and demonstrate the predicted negative cueing effects for the first time in this population.

Although error rates in standard picture naming are generally low for normal participants, effects of phonological cueing on picture naming performance have been observed (Nicholas, Obler, Albert, \& Goodglass, 1985), and these effects can be enhanced using the tempo naming paradigm (Hodgson \& Lambon Ralph, 2008), where items must be named in time with a specific rhythm or tempo. Using this technique, Hodgson and Lambon Ralph (2008, Experiment 2) observed a significant increase in picture naming errors amongst normal participants at a more rapid than usual tempo, including differential effects from correct and misleading phonemic cues. A comparison to more traditional deadline naming demonstrated a higher rate of semantic errors in tempo naming irrespective of response speed (Hodgson \& Lambon Ralph, Experiment 1). This suggests that the attention to the timing of the response could function to make tempo naming a kind of dual task (Collette, Olivier, et al., 2005; Newman, Keller, \& Just, 2007), diverting resources from an executive control capacity, and producing an increased sensitivity to cueing akin to that seen in SA patients. Hence the second aim of our study was to assess this hypothesis by testing the impact of positive and negative cueing upon the picture naming performance of a group of SA patients using precisely the same materials employed by Hodgson and Lambon Ralph (2008, Experiment 2), which are listed in Appendix B in the Supplementary Materials.

\section{Method}

\subsection{Participants}

Seven SA patients were recruited from stroke clubs or recommended by speech and language services in Greater Manchester, UK. They were a subset of those reported in other work on this patient group (Jefferies et al., 2007; Jefferies \& Lambon Ralph, 2006; Jefferies et al.,2008). Each patient had a chronic impairment from a CVA at least a year previous to the current study. Table 1 includes biographical details and detailed lesion information.

\subsubsection{Background neuropsychology and semantic testing}

As seen in Table 2, patients were tested on forward and backwards digit span (Wechsler, 1997), the Visual Object and Space Perception (VOSP) battery (Warrington \& James, 1991), the Coloured Progressive Matrices test of non-verbal reasoning (Raven, 1962). Executive skill and attention were tested with the Wisconsin Card Sorting test (Milner, 1964), the Brixton Spatial Rule Attainment task (Burgess \& Shallice, 1997), and Elevator Counting (with and without distraction) from the Test of Everyday Attention (Robertson, Ward, Ridgeway \& Nimmo-Smith, 1994), with a number of patients impaired on these measures. Phonological skill was assessed using word repetition from PALPA (Kay, Lesser, \& Coltheart, 1992): 5/7 showed strong performance ( $>91 \%$ ). Semantic skills were tested using a number of assessments, for example word and picture versions of PPT (Howard \& Patterson, 1992) and CCT (Bozeat et al., 2000). Other semantic tests comprised synonym judgement (Jefferies, Patterson, 
Table 2

Background neuropsychological assessment of SA patients.

\begin{tabular}{|c|c|c|c|c|c|c|c|c|c|c|}
\hline Task/test & Max & Normal cut-off ${ }^{\mathrm{a}}$ & NY & HN & JD & PG & SC & BB & ME & mean \\
\hline VOSP dot counting & 10 & 8 & 10 & 8 & 10 & 5 & 10 & 10 & 3 & 8 \\
\hline VOSP position discrimination & 20 & 18 & 20 & 19 & 20 & 20 & 17 & 18 & 15 & 18.43 \\
\hline VOSP number location & 10 & 7 & 10 & 9 & 10 & 9 & 10 & 8 & 2 & 8.29 \\
\hline VOSP cube analysis & 10 & 6 & 5 & 4 & 10 & 10 & 9 & 2 & 4 & 6.29 \\
\hline Raven's coloured matrices (percentiles) & & & 50 & 20 & 30 & 50 & 50 & 50 & $<5$ & 36.43 \\
\hline WCST (number of categories) & 6 & $1^{\mathrm{b}}$ & 2 & 6 & 1 & $\mathbf{0}$ & 6 & 1 & $\mathbf{0}$ & 2.29 \\
\hline Brixton spatial anticipation (correct) & 54 & 28 & 34 & 28 & 28 & 26 & 25 & 23 & 11 & 25 \\
\hline TEA counting without distraction & 7 & 6 & 3 & 7 & 7 & $\mathbf{0}$ & 7 & 4 & 7 & 5 \\
\hline TEA counting with distraction & 10 & 3 & 2 & 9 & 6 & 3 & 1 & $\mathbf{0}$ & 9 & 4.29 \\
\hline Digit span forwards & - & 5 & 3 & 6 & 5 & 6 & 6 & 5 & 6 & 5.29 \\
\hline Digit span backwards & - & 2 & 2 & 2 & 2 & 2 & 2 & $\mathbf{0}$ & 3 & 1.88 \\
\hline PALPA word repetition & 80 & 80 & 65 & 69 & 74 & 73 & 78 & 77 & 80 & 73.71 \\
\hline Picture PPT & 52 & 48.4 & 47 & 35 & 46 & 42 & 50 & 41 & 29 & 41.43 \\
\hline Word PPT & 52 & 48.9 & 42 & 44 & NT & 43 & 51 & 35 & 39 & 42.33 \\
\hline Synonym judgement & 96 & 90.1 & 69 & 70 & 73 & 69 & 71 & 63 & 81 & 70.86 \\
\hline Letter fluency & - & 21.8 & $\mathbf{5}$ & 19 & 5 & 2 & 24 & $\mathbf{0}$ & 14 & 9.86 \\
\hline Category fluency & - & 62.7 & 25 & 63 & 31 & 4 & 17 & 13 & 25 & 25.43 \\
\hline 64 Item Picture Naming & 64 & 59.1 & 55 & 50 & 49 & 46 & 28 & 10 & 5 & 34.71 \\
\hline 64 Item Spoken Word-picture Matching & 64 & 62.7 & 60 & 50 & 64 & 58 & 59 & 54 & 50 & 56.43 \\
\hline 64 Item Picture CCT & 64 & 52.7 & 36 & 54 & 38 & 44 & 46 & 38 & 13 & 38.43 \\
\hline 64 Item Word CCT & 64 & 56.6 & 39 & 54 & 38 & 40 & 56 & 30 & 34 & 41.57 \\
\hline
\end{tabular}

Patients are arranged in order of naming scores in the 64 item battery (Bozeat et al., 2000).

All impaired scores are shown in bold.

$\mathrm{NT}=$ Not taken.

${ }^{\mathrm{a}}$ For semantic tests, this represents the control mean - 2SD.

b Cut-off for 50-74 year olds (regardless of educational level).

Jones, \& Lambon Ralph, in press), and category and letter fluency. As shown in Table 2, all patients showed significant impairments across a range of semantic tests.

\subsection{Stimuli}

The picture stimuli and cues, both positive (correct initial phoneme) and negative (initial phoneme of a category co-ordinate), were those used by Hodgson and Lambon Ralph (2008). Testing was carried out in the patients' homes using a laptop. Each picture appeared simultaneously with its sound cue; it remained on screen until a response was given, and the tester repeated the sound cue when necessary.

\subsection{Procedure}

The experiment was presented using E-Prime (Schneider, Eschman, \& Zuccolotto, 2002), with participants sitting around $80 \mathrm{~cm}$ from the screen. There were three cueing conditions; correct (initial phoneme of target), neutral (short beep), and incorrect (initial phoneme of category co-ordinate). The entire test was split into three versions presented on three separate occasions, with the order of presentation of each version alternated across patients. Each version comprised 20 items presented with each cue type, yielding 60 trials per version. Across the three versions, each set of 20 items was rotated through all three cueing conditions, meaning that every item appeared in every condition, yielding 180 observations per patient by the end of the three testing sessions. Within each test session, the cue conditions were mixed randomly, so the cue type could not be predicted on each trial. Patients were informed that the task was simply to name the picture in all cases.

\section{Results}

The patients' first responses were scored and, following the method of Hodgson and Lambon Ralph (2008) any errors were coded as either semantic, omission or other (the complete error taxonomy can 


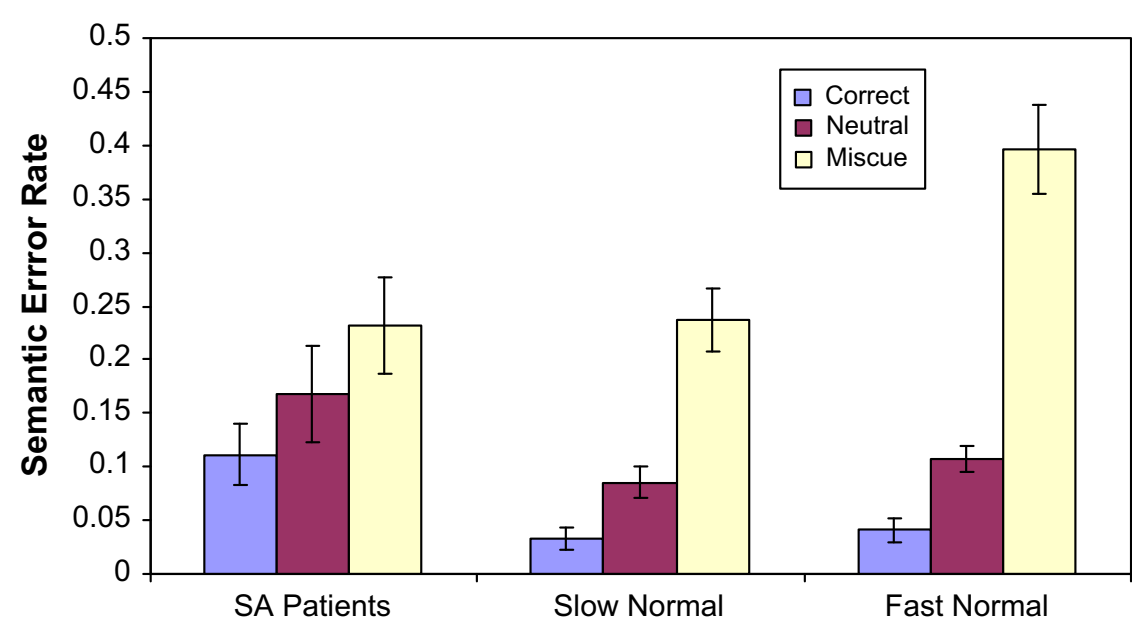

Fig. 1. Semantic error rates (proportions of trials/condition) in each cue condition for patients in the present study and the normal participants in the tempo naming study of Hodgson and Lambon Ralph (2008, Experiment 2). Error bars represent \pm standard error.

be found in Appendix C in the Supplementary Materials). The patients' scores were converted to a proportion of the number of trials per condition. As we had explicitly directional hypotheses concerning the effects of cueing, the $p$-values reported for the patient data are one-tailed, with all other $p$ values provided as two-tailed.

\subsection{Picture naming accuracy}

Naming accuracy data were initially analysed using a one-way repeated measures ANOVA on the variable cue type (correct/neutral/miscue). There was a significant effect on accuracy $(F(2,12)=5.22$; $p=.012$ ), with the highest accuracy seen for correct cues (.78), followed by neutral cues (.71), and then miscues (.62). Correct cues produced significantly more accurate responses than the miscues $(t(6)=2.75 ; p=.017)$; correct cues produced significantly more accurate responses than neutral cues $(t(6)=2.13 ; p=.039)$; and the disadvantage for the miscues relative to the neutral cues was marginally significant $(t(6)=1.70 ; p=.069)$.

\subsection{Semantic error rates}

Semantic errors (.17 of responses) were significantly more frequent than null responses $(.6, t(6)=3.30 ; p=.008)$ and other errors $(.7, t(6)=5.97 ; p<.001)$. As for accuracy, an ANOVA considering only semantic errors demonstrated a significant effect of cue type $(F(2,12)=3.86$; $p=.026)$, with fewest errors produced to correct cues (.11 of responses), followed by neutral cues (.17), and then miscues (.23), as can be seen in Fig. 1. Semantic error rates were significantly lower for correct cues than miscues $(t(6)=-2.47 ; p=.024)$, and also for correct cues than neutral cues $(t(6)=-2.20$; $p=.035)$. Although the difference between neutral cues and miscues was not reliable when all semantic errors were considered $(t(6)=-1.24 ; p=.131)$, this difference was significant when the proportions of semantic errors that corresponded to the particular category co-ordinates used in the miscue condition were compared ( $17 \%$ vs $32 \%$ respectively, $t(6)=-2.26 ; p=.032$ ).

\subsection{Comparison with tempo picture naming}

As in the patient data above, Hodgson and Lambon Ralph (2008, Experiment 2) found semantically related responses to be the most common form error in their participants, so only these responses will be considered here. Fig. 1 shows the comparison of semantic error rates for the SA patients and the normal participants in each tempo condition. A two-way ANOVA with cue type (correct/neutral/ miscue) as a within participants factor and group (patient/normal) as a between participants factor was conducted for each tempo condition. 
Consideration of the slow tempo showed that the patients made marginally more semantic errors than the normal participants (.17 vs $.12, F(1,32)=3.59 ; p=.067)$. Cue type significantly affected semantic error rates $(F(2,64)=15.57 ; p<.001)$, with most semantic errors to miscues $(.23)$, then neutral cues (.13), and correct cues (.07). The interaction of this cueing effect with group was not significant $(F(2,64)=1.66, p=.199)$. As can be seen in Fig. 1, for normal participants at the slow tempo, fewest errors were produced to correct cues (.03), followed by neutral cues (.09), and then miscues (.24). Semantic error rates were significantly lower for correct cues than miscues $(t(26)=-6.15$; $p<.0005)$, for correct cues than neutral cues $(t(26)=-3.02 ; p=.006)$, and for neutral cues than miscues $(t(26)=-5.00 ; p<.0005)$.

Consideration of the fast tempo showed that the patients and normal participants produced a comparable number of semantic errors (.17 vs $.18, F(1,32)<1)$. Cue type significantly affected semantic error rates $(F(2,64)=24.09 ; p<.001)$, with most semantic errors to miscues $(.31)$, then neutral cues (.14), and correct cues (.08). However, there was also a significant interaction between cue type and group $(F(2,64)=7.03 ; p=.009)$. As can be seen in Fig. 1, for normal participants at the fast tempo, fewest errors were produced to correct cues (.04), followed by neutral cues (.11), and then miscues (.40). Semantic error rates were significantly lower for correct cues than miscues $(t(26)=-8.51 ; p<.0005)$, for correct cues than neutral cues $(t(26)=-5.31 ; p<.0005)$, and for neutral cues than miscues $(t(26)=-7.22 ; p<.0005)$. Comparisons concerning group differences revealed that in response to the correct cue, patients produced significantly more semantic errors than normals (.11 vs $.04, t(32)=2.72 ; p=.011)$; in the neutral condition, patients tended to make more semantic errors than normals (.17 vs $.11, t(32)=1.89, p=.068$ ); in the miscue condition, patients actually produced substantially fewer semantic errors than normals (.23 vs .40, $t(32)=-1.95 ; p=.060$ ).

\section{Discussion}

In accordance with the hypothesis that semantic control deficits make patients more susceptible to manipulations such as phonological cueing, our data show that giving a correct cue to SA aphasic patients resulted in significantly more accurate responses than either a neutral or an incorrect cue. This supports previous work where cueing has been shown to have a beneficial effect for SA patients (Jefferies et al., 2007, 2008) and extends it by demonstrating the impact of miscueing with the initial phoneme of a category co-ordinate for the first time in this patient group. These cueing effects are consistent with the working hypothesis that this subset of patients have intact semantic representations but do not utilise them in a task appropriate way (Jefferies \& Lambon Ralph, 2006; Noonan et al., in press). Further support is given to this idea by the strong correlations obtained between the cueing effects seen in overall accuracy and performance on the measures of executive functioning provided in Table 2 (overall cueing effect and WCST: $\rho=-.824, p=.011$; positive cueing effect and Brixton: $\rho=-.883, p=.004$; negative cueing effect and TEA without distraction: $\rho=-.670, p=.050$ )

The cueing effects we obtained were largely driven by differences in semantic error rates, consistent with the view that these patients' anomia arises from their semantic control impairment. The presentation of misleading phonemes did not appear to disrupt the phonological integrity of patients' responses, as there was a very low level of phonological errors (.003 as proportion of all trials), suggesting that phonological representations and processing are relatively intact in these patients. Thus, as predicted, it would seem that the phonological cues provide an external influence that either appropriately or inappropriately constrains the semantic activation driving picture naming. While we are of the view that semantic control is underpinned by a network of frontal and temporo-parietal regions, consideration of Table 1 shows that although frontal lesions were not universal, damage to the temporo-parietal cortex or the white matter immediately beneath is was common to all patients.

The cueing effects we observed in the semantic error rates of SA patients were in fact comparable to those reported by Hodgson and Lambon Ralph (2008, Experiment 2) for their slow tempo of $800 \mathrm{~ms}$. This supports their hypothesis that the tempo naming procedure itself places a load on executive processing in normal participants, using resources which would otherwise be available to direct semantic activation, including inhibition of competing semantic representations. Strikingly, for the faster tempo of $600 \mathrm{~ms}$, the cueing effects observed for the normal participants were in fact significantly larger than those obtained in this patient group. This result could be seen as a reflection of the 
integrity of the semantic control processes operating amongst the normal individuals, such that activation of both correct targets and competitors in response to an initial phoneme cue is highly efficient.

\subsection{Implications for models of speech production}

It is our view that cascading activation and interactive feedback could allow phonological cues to influence semantic processing (Dell \& O'Seaghdha, 1992; Dell, Schwartz, Martin, Saffran, \& Gagnon, 1997; Foygel \& Dell, 2000; Rapp \& Goldrick, 2000; Schwartz, Dell, Martin, Gahl, \& Sobel, 2006). Cascading activation refers to a process in which activation of several semantic candidates flows to phonology before a target has been selected for production. Interactive feedback reverberates between semantic and phonological processing, so phonemic cues can boost the activation of semantic representations which are consistent with them (Dell et al., 1997; Foygel \& Dell, 2000; Lambon Ralph, Moriarty, \& Sage, 2002; Lambon Ralph et al., 2000). In these models, the correct cue both promotes the target and demotes competitors. Miscues, by contrast, will promote one of the semantically-related items at the cost of the target name. For example, on viewing a picture of a TIGER, semantic representations of related large felines like PUMA, LION and LEOPARD receive partial activation (Damian \& Martin, 1999; Dell et al., 1997; Foygel \& Dell, 2000; Lambon Ralph et al., 2000). All the potential candidates begin to activate their phonological forms and normally the target leads this phonological "race". If the correct cue / $\mathrm{t}$ / is provide, it will boost activation of target "tiger" at both the semantic and phonological levels, meaning that it is more likely to reach threshold, and to do so sooner, than if no cue had been given: hence the advantage for the correct cue condition. If, however, the incorrect cue / $1 /$ has been given, the semantic and phonological representations of alternative responses such as "lion" or "leopard" will be activated, which may cause them to reach threshold sooner than the correct target, resulting in a semantic error, hence the disadvantage in the miscue condition.

The miscueing effect we have reported here could be considered as comparable to the disadvantage obtained with semantically related distractors in the picture word interference paradigm, when the stimulus onset asynchrony between picture and distractor is either simultaneous or $+/-100 \mathrm{~ms}$ (Caramazza \& Costa, 2000, 2001; Costa, Alario, \& Caramazza, 2005; Glaser \& Glaser, 1989; Levelt, Roelofs, \& Meyer, 1999; Wilshire, Keall, Stuart, \& O’Donnell, 2007; de Zubaricay, Wilson, McMahon, \& Muthiah, 2001). However, the crucial difference is that in our cued naming paradigm, only a single distractor phoneme is presented, whereas in picture word interference, a whole distractor word is provided.

Although a discrete feedforward serial model of speech production such as that proposed by Levelt et al. (1999) may be able to accommodate effects of single phoneme cues on RT, it does not seem to incorporate any mechanism by which such cues could affect accuracy, at least on the assumption that perception of a phonemic cue does not activate all of the semantic representations consistent with it. Even without biasing semantic activation, a correct phonemic cue might speed word form assembly once the selected lemma has passed to phonology. However, if the incorrect lemma is selected at the semantic level, then pre-activation of the correct initial phoneme at the phonological level would merely slow production of an incorrect response. Similarly, even if a miscue does not affect semantic activation, the pre-activation of an incorrect phoneme at the phonological level will delay activation of the phonemes of the target lemma. Nonetheless, most of the phonemes of the correct response should eventually become activated, meaning that this account cannot explain why almost a third of the patients' errors (32\%) in the miscue condition comprised the miscued competitor (e.g. "lion" for TIGER). We therefore propose that models of speech production incorporating cascaded and interaction processing provide a more natural and parsimonious explanation of the cueing effects seen in the accuracy of SA patients and normal participants under tempo naming conditions.

In summary, the presentation of phonemic cues and miscues was successful in affecting picture naming accuracy in a case series of SA patients with semantic control impairments. Given the similarity of the patients' performance to that of normal participants under slow tempo conditions, support was given to the hypothesis that the tempo paradigm itself, rather than the more rapid responding that it can be used to induce, is effective in disrupting semantic control processes and thereby mimicking SA patient performance. 


\section{Appendix. Supplementary information}

Supplementary information associated with this article can be found, in the online version, at doi:10.1016/j.jneuroling.2009.06.002.

\section{References}

Berthier, M. (2001). Unexpected brain-language relationships in aphasia: evidence from transcortical sensory aphasia associated with frontal lobe lesions. Aphasiology, 15(2), 99-130.

Bozeat, S., Lambon Ralph, M., Patterson, K., \& Hodges, J. (2000). Non-verbal semantic impairment in semantic dementia. Neuropsychologia, 38(9), 1207-1215.

Bozeat, S., Ralph, M. A. L., Graham, K. S., Patterson, K., Wilkin, H., Rowland, J., et al. (2003). A duck with four legs: investigating the structure of conceptual knowledge using picture drawing in semantic dementia. Cognitive Neuropsychology, 20(1), 27-47.

Burgess, P., \& Shallice, T. (1997). The Hayling and Brixton tests. Thurston, Suffolk: Thames Valley Test Company.

Caramazza, A., \& Costa, A. (2000). The semantic interference effect in the picture-word interference paradigm: does the response set matter? Cognition, 75(2), B51-B64.

Caramazza, A., \& Costa, A. (2001). Set size and repetition in the picture-word interference paradigm: implications for models of naming. Cognition, 80(3), 291-298.

Chertkow, H., Bub, D., Deaudon, C., \& Whitehead, V. (1997). On the status of object concepts in aphasia. Brain and Language, $58(2), 203-232$

Collette, F., Hogge, M., Salmon, E., \& Van der Linden, M. (2006). Exploration of the neural substrates of executive functioning by functional neuroimaging. Neuroscience, 139(1), 209-221.

Collette, F., Olivier, L., Van der Linden, M., Laureys, S., Delfiore, G., Luxen, A., et al. (2005). Involvement of both prefrontal and inferior parietal cortex in dual-task performance. Cognitive Brain Research, 24(2), 237-251.

Collette, F., Van der Linden, M., Laureys, S., Delfiore, G., Degueldre, C., Luxen, A., et al. (2005). Exploring the unity and diversity of the neural substrates of executive functioning. Human Brain Mapping, 25(4), 409-423.

Costa, A., Alario, F., \& Caramazza, A. (2005). On the categorical nature of the semantic interference effect in the picture-word interference paradigm. Psychonomic Bulletin and Review, 12(1), 125-131.

Cristescu, T. C., Devlin, J. T., \& Nobre, A. C. (2006). Orienting attention to semantic categories. Neuroimage, 33(4), $1178-1187$.

Damian, M., \& Martin, R. (1999). Interactivity of semantic and phonological factors in speech production. Journal of Experimental Psychology: Learning, Memory \& Cognition, 25(2), 345-361.

Dell, G., \& O'Seaghdha, P. (1992). Stages of lexical access in language production. Cognition, 42(1-3), 287-314.

Dell, G., Schwartz, M., Martin, N., Saffran, E., \& Gagnon, D. (1997). Lexical access in aphasic and nonaphasic speakers. Psychological Review, 104, 801-838.

Devlin, J. T., Matthews, P. M., \& Rushworth, M. F. S. (2003). Semantic processing in the left inferior prefrontal cortex: a combined functional magnetic resonance imaging and transcranial magnetic stimulation study. Journal of Cognitive Neuroscience, 15(1), 71-84

Foygel, D., \& Dell, G. S. (2000). Models of impaired lexical access in speech production. Journal of Memory and Language, 43, $182-216$.

Glaser, W., \& Glaser, M. (1989). Context effect in stroop-like word and picture processing. Journal of Experimental PsychologyGeneral, 118, 13-42.

Hodgson, C., \& Lambon Ralph, M. (2008). Mimicking aphasic semantic naming errors in normal speech production: evidence from a novel experimental paradigm. Brain and Language, 104(1), 89-101.

Howard, D., \& Gatehouse, C. (2006). Distinguishing semantic and lexical word retrieval deficits in people with aphasia. Aphasiology, 20(9-11), 921-950.

Howard, D., \& Orchard-Lisle. (1984). On the origin of semantic errors in naming: evidence from the case of a global aphasic. Cognitive Neuropsychology, 1, 163-190.

Howard, D., \& Patterson, K. (1992). Pyramids and palm trees: A test of semantic access from pictures and words. Bury St. Edmonds, UK: Thames Valley Test Company.

Jefferies, E., Baker, S. S., Doran, M., \& Lambon Ralph, M. A. (2007). Refractory effects in stroke aphasia: a consequence of poor semantic control. Neuropsychologia, 45(5), 1065-1079.

Jefferies, E., \& Lambon Ralph, M. (2006). Semantic impairment in stroke aphasia versus semantic dementia: a case-series comparison. Brain, 129(8), 2132-2147.

Jefferies, E., Patterson, K., Jones, R., \& Lambon Ralph, M. Comprehension of concrete and abstract words in semantic dementia. Neuropsychology, in press.

Jefferies, E., Patterson, K., \& Lambon Ralph, M. (2008). Deficits of knowledge versus executive control in semantic cognition: Insights from cued naming. Neuropsychologia, 46, 649-658.

Kay, J., \& Ellis, A. (1987). A cognitive neuropsychological case study of anomia: implications for psychological models of word retrieval. Brain, 110, 613-629.

Kay, J., Lesser, R., \& Coltheart, M. (1992). Psycholinguistic assessments of language processing in aphasia (PALPA). Hove, UK: Lawrence Erlbaum Associates.

Lambon Ralph, M., Moriarty, L., \& Sage, K. (2002). Anomia is simply a reflection of semantic and phonological impairments: evidence from a case-series study. Aphasiology, 16(1-2), 56-82.

Lambon Ralph, M., Sage, K., \& Roberts, J. (2000). Classical anomia: a neuropsychological perspective on speech production. Neuropsychologia, 38(2), 186-202.

Levelt, W. J., Roelofs, A., \& Meyer, A. S. (1999). A theory of lexical access in speech production. Behavioral and Brain Sciences, 22(1), 1-75. 
Milner, B. (1964). Effects of different brain lesions on card sorting - role of frontal lobes. Archives Of Neurology, 9(1), 100-110. Newman, S. D., Keller, T. A., \& Just, M. A. (2007). Volitional control of attention and brain activation in dual task performance. Human Brain Mapping, 28(2), 109-117.

Nicholas, M., Obler, L., Albert, M., \& Goodglass, H. (1985). Lexical retrieval in healthy aging. Cortex, 21, 595-606.

Noonan, K., Jefferies, E., Corbett, F., Hopper, S., \& Lambon Ralph, M. Elucidating the nature of deregulated semantic cognition in semantic aphasia: evidence for the roles of prefrontal and temporoparietal cortices. Journal of Cognitive Neuroscience, in press.

Peers, P. V., Ludwig, C. J. H., Rorden, C., Cusack, R., Bonfiglioli, C., Bundesen, C., et al. (2005). Attentional functions of parietal and frontal cortex. Cerebral Cortex, 15(10), 1469-1484.

Rapp, B., \& Goldrick, M. (2000). Discreteness and interactivity in spoken word production. Psychological Review, 107, $460-499$. Raven, J. C. (1962). Coloured progressive matrices: Sets A, AB, B. London: Lewis.

Robertson, I. H., Ward, T., Ridgeway, V., \& Nimmo-Smith, I. (1994). The test of everyday attention. Flempton: Thames Valley Test Company.

Rogers, T., Lambon Ralph, M., Garrard, P., Bozeat, S., McClelland, J., Hodges, J., et al. (2004). Structure and deterioration of semantic memory: a neuropsychological and computational investigation. Psychological Review, 111(1), 205-235.

Schneider, W., Eschman, A., \& Zuccolotto, A. (2002). E-prime user's guide. Pittsburgh: Psychology Software Tools, Inc.

Schwartz, M., Dell, G., Martin, N., Gahl, S., \& Sobel, P. (2006). A case-series test of the interactive two-step model of lexical access: evidence from picture naming. Journal of Memory and Language, 54(2), 228-264.

Warrington, E., \& James, M. (1991). Visual object and space perception. London: Pearson Assessment.

Wechsler, D. (1997). The Wechsler adult intelligence scale (3rd ed.). San Antonio, TX: Psychological Corporation.

Wilshire, C. E., Keall, L. M., Stuart, E. J., \& O’Donnell, D. J. (2007). Exploring the dynamics of aphasic word production using the picture-word interference task: a case study. Neuropsychologia, 45(5), 939-953.

Woollams, A., Cooper-Pye, E., Hodges, J., \& Patterson, K. (2008). Anomia: a doubly typical signature of semantic dementia. Neuropsychologia, 46, 2503-2514.

de Zubaricay, G., Wilson, S., McMahon, K., \& Muthiah, S. (2001). The semantic interference effect in the picture-word paradigm: an event related fMRI study employing overt responses. Human Brain Mapping, 14, 218-227. 